\title{
Correction to: Presynaptic Ethanol Actions: Potential Roles in Ethanol Seeking
}

David M. Lovinger

\section{Correction to: Seeking" in: D. M. Lovinger, Handbook of Experimental Pharmacology, https://doi.org/10.1007/164_2017_76}

Chapter "Presynaptic Ethanol Actions: Potential Roles in Ethanol

The Acknowledgements unfortunately went missing to be included in the chapter. It has been included now. This work was supported by the Division of Intramural Clinical and Biological Research of the National Institute on Alcohol Abuse and Alcoholism, project ZIA AA000407. The original chapter has been corrected.

The updated online version of this chapter can be found at https://doi.org/10.1007/164_2017_76 